\title{
Peningkatan Hasil Belajar Siswa Dengan Model Discovery Learning Berbantuan Zoom Pada Mata Pelajaran Bahasa Indonesia Kelas V Sekolah Dasar
}

\section{Risa Arum Mardiatama}

SDN Sumberagung 01

risa.arum.mardiatama@gmail.com

\section{Article History}

received 3/12/2020

accepted 31/12/2020

\begin{abstract}
The learning outcomes of students of class V SDN Sumberagung 01 on the subjects of Bahasa Indonesia is still low. The cause is the activity of student learning is low and the use of learning model that is less varied. The purpose of this research is to improve student learning outcomes in subjects Bahasa Indonesia kelas V SDN Sumberagung 01 school year 2019/2020 through model Discovery learning assisted Zoom. The subject of research is the students of class V SDN Sumberagung 01, with the number of students as many as 10 children. The Data in this research is data about the improvement of learning outcomes of Indonesian Language through the use of model discovery learning assisted Zoom. The results showed that the application of the model the model of Discovery learning assisted Zoom can increase the mastery learning students. Learning outcomes students ranging from thepre-cycle to the second cycle in a row increased, i.e. $30 \%, 50 \%$, and $90 \%$ with the average 59,00, 65.70, and 89,90.
\end{abstract}

keywords: learning outcomes, discovery learning

\begin{abstract}
Abstrak
Hasil belajar peserta didik kelas V SDN Sumberagung 01 pada mata pelajaran Bahasa Indonesia masih rendah. Penyebabnya yaitu aktivitas belajar siswa rendah dan penggunaan model pembelajaran yang kurang variatif. Tujuan penelitian ini yaitu untuk meningkatkan hasil belajar siswa pada mata pelajaran Bahasa Indonesia kelas V di SDN Sumberagung 01 tahun pelajaran 2019/2020 melalui model discovery learning berbantuan Zoom. Subjek penelitian adalah peserta didik kelas V SDN Sumberagung 01, dengan jumlah peserta didik sebanyak 10 anak. Data dalam penelitian adalah data tentang peningkatan hasil belajar Bahasa Indonesia melalui penggunaan model Discovery learning berbantuan Zoom. Hasil penelitian menunjukkan bahwa penerapan model model Discovery learning berbantuan Zoom dapat meningkatkan ketuntasan belajar peserta didik. Hasil belajar siswa mulai dari prasiklus sampai siklus II berturutturut mengalami peningkatan, yaitu 30\%, 50\%, dan 90\% dengan rata - rata 59,00, 65.70 , dan 89,90 .
\end{abstract}

Kata kunci: hasil belajar, discovery learning

Social, Humanities, and Education Studies (SHEs): Conference Series https://jurnal.uns.ac.id/shes

p-ISSN 2620-9284 e-ISSN 2620-9292 


\section{PENDAHULUAN}

Pendidikan adalah usaha sadar dan terencana untuk mewujudkan suasana belajar dan proses pembelajaran agar peserta didik secara aktif mengembangkan potensi dirinya untuk memiliki kekuatan spiritual, kecerdasan, akhlak mulia, serta keterampilan yang diperlukan dirinya, masyarakat, bangsa, dan negara (Undangundang Sisdiknas No. 20 Tahun 2003). Dalam penyelenggaraan pendidikan di sekolah dasar saat ini, menerapkan sistem pembelajaran tematik terpadu. Pembelajaran tematik terpadu merupakan pembelajaran menggunakan tema untuk mengaitkan beberapa muatan mata pelajaran agar dapat memberikan pengalaman bermakna kepada peserta didik.

Bahasa Indonesia merupakan salah satu mata pelajaran yang wajib dipelajari di sekolah dasar. Selain itu juga bahasa digunakan sebagai alat komunikasi dalam kehidupan sehari-hari. Keraf (1984:15) memberikan dua pengertian bahasa,yaitu: pengertian pertama menyatakan bahasa sebagai alat komunikasi antara anggota masyarakat berupa simbol bunyi yang dihasilkan oleh alat ucap manusia. kedua, bahasa adalah sistem komunikasi yang mempergunakan simbol-simbol vokal (bunyi ujaran) yang bersifat arbitrer.

Dalam pembelajaran Bahasa Indonesia dikenal empat kemampuan berbahasa yang harus dikuasai siswa yaitu : menyimak, membaca, berbicara dan menulis. Keempat kemampuan itu memiliki peranan yang sangat penting bagi manusia karena dengan keempat kemampuan itu manusia akan dapat berkomunikasi dengan manusia lainnya baik secara langsung maupun tidak langsung.

Berdasarkan pengamatan saya pada proses pembelajaran daring di kelas $\mathrm{V}$ SDN Sumberagung 01 terdapat permasalahan pada pembelajaran Bahasa Indonesia. Hal tersebut terlihat dari hasil Tes Tengah Semester Gasal Tahun Pelajaran 2019/2020. Dari kriteria ketuntasan minimal Bahasa Indonesia yaitu 70 terdapat 7 siswa dari 10 siswa yang belum mencapai nilai KKM atau bisa dikatakan 30\% siswa yang mendapatkan nilai lebih dari atau sama dengan 70 . Hal tersebut mencerminkan bahwa siswa belum mampu memahami dengan baik materi yang disampaikan. Hal tersebut disebabkan oleh: 1) aktivitas belajar siswa rendah; 2) penggunaan model pembelajaran yang kurang variatif; 3) siswa juga merasa bosan belajar lewat gawai mereka yang sekedar menyaksikan video youtub atau PPT, maka dari itu peneliti akan melakukan penelitian tindakan kelas dalam mata pelajaran Bahasa Indonesia menggunakan model Discovery learning berbantuan zoom di kelas $\mathrm{V}$ SDN Sumberagung 01.

Discovery learning adalah teori belajar yang didefinisikan sebagai proses pembelajaran yang terjadi bila pelajar tidak disajikan dengan pelajaran dalam bentuk finalnya, tetapi diharapkan siswa mengorganisasi sendiri. Sebagai strategi belajar, Discovery learning mempunyai prinsip yang sama dengan inkuiri (inquiry) dan Problem Solving. Langkah-Langkah Operasional dalam Discovery learnig adalah: Stimulation (stimulasi/pemberian rangsangan); Problem statement (pernyataan/ identifikasi masalah); Data collection (Pengumpulan Data); Data Processing (Pengolahan Data); Verification (Pembuktian). Sedangkan zoom adalah aplikasi yang menyediakan layanan konferensi jarak jauh dengan menggabungkan konferensi video, pertemuan online, obrolan, hingga kolaborasi seluler. Aplikasi ini dapat membantu guru dalam melakukan pembelajaran syncrounus dengan siswa. 


\section{METODE}

Penelitian yang dilakukan adalah Penelitian Tindakan Kelas (PTK). PTK adalah bentuk penelitian yang mengangkat masalah-masalah aktual dalam pembelajaran di kelas. Penelitian ini berupa tindakan untuk memperbaiki dan meningkatkan praktik pembelajaran di kelas. Penelitian ini menggunakan desain PTK dengan dua siklus yaitu proses tindakan pada siklus I dan siklus II. Siklus I bertujuan untuk mengetahui kemampuan menyusun teks laporan hasil observasi siswa dan siklus II bertujuan untuk mengetahui peningkatan kemampuan menyusun teks laporan hasil observasi setelah dilakukan perbaikan dalam kegiatan belajar mengajar yang didasarkan pada refleksi siklus I. Menurut Kurt Lewin dalam Kunandar (2011: 42) penelitian tindakan kelas ini terdiri dari empat tahapan dasar, yaitu perencanaan, tindakan, pengamatan, dan refleksi. Keempat komponen tersebut dipandang sebagai I siklus. Penelitian ini diawali dengan pre tes terlebih dahulu. Setelah mengetahui kondisi awal siswa, kemudian dilakukan tindakan siklus I sebagai upaya perbaikan. Tindakan siklus II agar terjadi peningkatan hasil siswa. Proses penelitian tindakan kelas ini dapat digambarkan sebagai Subjek Penelitian. Teknik pengumpulan data yang dilakukan dengan observasi dan tes, baik pre test maupun post test. Observasi meliputi observasi keterlaksanaan model pembelajaran Discovery learning, sikap peserta didik dan keterampilan. Untuk hasil belajar menggunakan tes melalui Google form.

\section{HASIL DAN PEMBAHASAN}

Penelitian ini dilaksanakan di SDN Sumberagung 01 Kecamatan Jaken Kabupaten Pati. Adapun yang menjadi objek penelitian adalah hasil belajar Bahasa Indonesia pada siswa kelas V SDN Sumberagung 01 menggunakan model Discovery learning. Hasil belajar Bahasa Indonesia siswa kelas V SDN Sumberagung 01 sebelum dilakukan tindakan adalah sebagai berikut:

Tabel 1. Hasil Belajar Siswa Pra Siklus

\begin{tabular}{ccccc}
\hline \multirow{2}{*}{ Jumlah Siswa } & Pra Siklus & & \\
& Pesdik Tuntas & $\%$ & $\begin{array}{c}\text { Pesdik Belum } \\
\text { Tuntas }\end{array}$ & $\%$ \\
\hline 10 & 3 & $30 \%$ & 7 & $70 \%$ \\
\hline
\end{tabular}

Berdasarkan data hasil belajar pra siklus di atas, maka diperoleh data bahwa hasil belajar Bahasa Indonesia kelas V SDN Sumberagung 01 dari 10 orang siswa baru 3 orang siswa $(30 \%)$ yang dinyatakan tuntas dengan nilai $\geq 70$, sehingga diperlukan tindakan pembelajaran melalui model Discovery learning.

Tabel 2. Hasil Belajar Siswa Siklus I

\begin{tabular}{ccccc}
\hline \multirow{2}{*}{ Jumlah Siswa } & Pesdik Tuntas & $\%$ & $\begin{array}{c}\text { Pesdik Belum } \\
\text { Tuntas }\end{array}$ & $\%$ \\
\hline 10 & 5 & $50 \%$ & 5 & $50 \%$ \\
\hline
\end{tabular}

Berdasarkan data hasil belajar siklus I di atas, peserta didik mengalami peningkatan hasil belajar bahasa indonesia yaitu sebanyak 5 peserta didik (50\%) yang tuntas dengan nilai $\geq 70$, namun masih ada 5 siswa (50\%) yang belum tuntas.

Berdasarkan hasil refleksi siklus I, peneliti akan mengontrol kembali proses pembelajaran yang akan dilaksanakan pada siklus II. Sebelum melakukan perbaikan 
pembelajaran pada siklus II, peneliti akan melakukan persiapan atau perencanaan ulang, agar hasil perbaikan pembelajaran siklus II dapat lebih baik dari siklus I.

Tabel 3. Hasil Belajar Siswa Siklus II

\begin{tabular}{ccccc}
\hline \multirow{2}{*}{ Jumlah Siswa } & \multicolumn{4}{c}{ Pra Siklus } \\
& Pesdik Tuntas & $\%$ & $\begin{array}{c}\text { Pesdik Belum } \\
\text { Tuntas }\end{array}$ & $\%$ \\
\hline 10 & 9 & $90 \%$ & 1 & $10 \%$ \\
\hline
\end{tabular}

Berdasarkan data hasil belajar siklus II di atas, peserta didik mengalami peningkatan hasil belajar Bahasa Indonesia yang signifikan yaitu sebanyak 9 peserta didik $(90 \%)$ yang tuntas dengan nilai $\geq 70$, sedangkan yang belum tuntas sebanyak 1 peserta didik (10\%).

Secara keseluruhan peningkatan hasil belajar Bahasa Indonesia pada peserta didik kelas V SDN Sumberagung 01 sebesar 60\%. Dari data awal pra siklus menunjukkan hanya 3 peserta didik yang tuntas (30\%), namun setelah dilaksanakan perbaikan pembelajaran secara bertahap menjadi 9 peserta didik yang tuntas $(90 \%)$, dari 10 jumlah peserta didik dalam satu kelas pada siklus II.

Penelitian ini tentang peningkatan hasil belajar siswa kelas $\mathrm{V}$ menggunakan model pembelajaran Discovery learning berbantuan zoom dapat dikatakan berhasil jika hasil belajar individual minimal $\geq 70$ dan ketuntasan klasikal minimal $75 \%$ dari jumlah siswa kelas V SDN Sumberagung 01 tahun pelajaran 2019/2020.

Penelitian ini dapat membuktikan bahwa penggunaan model Discovery learning berbantuan zoom dapat meningkatkan hasil belajar Bahasa Indonesia pada siswa kelas V SDN Sumberagung 01.

Hipotesis tindakan dalam penelitian ini terbukti bahwa penggunaan model discovery learning berbantuan zoom pada mata pelajaran Bahasa Indonesia dapat meningkat dengan ketuntasan hasil belajar individual minimal $\geq 70$ dan ketuntasan klasikal minimal 75\% dari jumlah siswa kelas V SDN Sumberagung 01 tahun pelajaran 2019/2020.

\section{SIMPULAN}

Langkah - langkah penggunaan model Discovery learning berbantuan zoom pada siswa kelas V di SDN Sumberagung 01 tahun pelajaran 2019/2020 pada mata pelajaran Bahasa Indonesia yang dilakukan oleh peneliti sebagai berikut : 1) Guru memberikan rangsangan, memulai kegiatan PBM dengan mengajukan pertanyaan, anjuran membaca buku, dan aktivitas belajar lainnya yang mengarah pada persiapan pemecahan masalah, 2) guru memberikan kesempatan kepada siswa untuk mengidentifikasi masalah yang relevan dengan bahan pelajaran, 3) guru memberi kesempatan kepada para siswa untuk mengumpulkan informasi, 4) siswa mengolah data dan informasi yang diperoleh melalui wawancara, observasi, dan sebagainya, lalu ditafsirkan. 5) Peserta didik melakukan pemeriksaan secara cermat untuk membuktikan benar atau tidaknya,6) Peserta didik dengan bantuan guru menarik kesimpulan yang dapat dijadikan prinsip umum dan berlak untuk semua kejadian atau masalah yang sama, dengan memperhatikan hasil verifikasi.

Peningkatan hasil belajar Bahasa Indonesia pada siswa kelas V SDN Sumbergung 01 melalui penggunaan model pembelajaran Discovey learning sejauh $60 \%$. Hal ini dibuktikan dari hasil nilai tes yang diperoleh siswa, yaitu pra siklus siswa yang tuntas $30 \%$ (3 siswa) menjadi 50\% (5 siswa) pada siklus I. Kemudian meningkat pada siklus II, siswa yang tuntas $90 \%$ (9 siswa) dari 10 siswa. 


\section{DAFTAR PUSTAKA}

Arikunto, Suhardjono dan Supardi. 2006. Penelitian Tindakan Kelas. Jakarta: Bumi Aksara.

Arikunto, Suharsimi. 2010. Prosedur Penelitian. Jakarta: PT Rineka Cipta.

Aqib, Zainal, dkk. 2011. Penelitian Tindakan Kelas untuk Guru SD, SLB, dan TK. Bandung: Yrama Widya.

Forijad. 1989. Penelitian dan Evaluasi Belajar. Jakarta: Karya Bersama.

Hopkins, David. 1993. A Teacher's Guide to Classroom Research. Philadelphia: Open University Press.

Keraf, Gorys. 1984. Diksi dan Gaya Bahasa. Jakarta: Gramedia

Kunandar. 2011. Langkah Mudah Penelitian Tindakan Kelas Sebagai Pengembang Profesi Guru. Jakarta: PT Raja Grafindo Persada.

Mulyatiningsih, Endang. 2011. Model Penelitian Terapan Bidang Pendidikan. Bandung: Alfabeta.

Padmono, Y. 2010. Kekurangan dan kelebihan, Manfaat Penerapan PTK. Online: edukasi.kompasiana.com.

Sudjana, N. 2005. Pembinaan dan Pengembangan kurikulum di Sekolah. Jakarta: Sinar Baru Algensindo.

Sugiono. 2011. Metode Penelitian Kuantitatif, Kualitatif dan R \& D. Bandung : Alfabeta. Suparno. 2008. Ketrampilan Dasar Menulis.Jakarta : Universitas Terbuka

Suprijono.2010. Cooperative Learning. Jakarta : Bumi Aksara.

Syah, Muhibbin. 2010. Psikologi Pendidikan Dengan Pendekatan Baru. Bandung: PT Remaja Rosdakarya.

Winaputra, S. Udin dkk. 2007. Teori Belajar dan Pembelajran. Jakarta: Pusat

Penerbitan Universitas Terbuka. 